\begin{tabular}{|c|c|}
\hline Title & Plasma and urine levels of electrolytes, urea and steroid hormones involved in osmoregulation of cetaceans \\
\hline Author(s) & $\begin{array}{l}\text { Birukawa, Naoko; A ndo, Hironori; Goto, Mutsuo; Kanda, Naohisa; Pastene, Luis A .; Nakatsuji, Hiroki; Hata, Hiroshi; } \\
\text { Urano, A kihisa }\end{array}$ \\
\hline Citation & $\begin{array}{l}\text { Zoological Science, 22(11), 1245-1257 } \\
\text { https://doi.org/10.2108/2sj.22.1245 }\end{array}$ \\
\hline Issue Date & $2005-11$ \\
\hline Doc URL & http:/hdl.handle.net/2115/13463 \\
\hline Type & article (author version) \\
\hline File Information & ZS2005BirukawaMS.pdf \\
\hline
\end{tabular}

Instructions for use 


\section{Plasma and urine levels of electrolytes, urea and steroid hormones involved in osmoregulation of cetaceans}

Naoko Birukawa ${ }^{1}$, Hironori Ando ${ }^{1}$, Mutsuo Goto ${ }^{2}$, Naohisa Kanda ${ }^{2}$, Luis A. Pastene ${ }^{2}$, Hiroki Nakatsuji ${ }^{3}$, Hiroshi Hata ${ }^{3}$ and Akihisa Urano ${ }^{1,3}$

${ }^{1}$ Division of Biological Sciences, Graduate school of Science, Hokkaido University, Sapporo, Hokkaido 060-0810, Japan,

${ }^{2}$ The Institute of Cetacean Research, Toyomi Shinko Bldg., 4-5, Toyomi-cho, Chuo-ku, Tokyo 104-0055, Japan,

${ }^{3}$ Field Science Center for Northern Biosphere, Hokkaido University, Sapporo, Hokkaido 060-0811, Japan.

Abbreviated title: Plasma and urine chemistry in cetaceans

Section: Physiology

Corresponding author: Naoko Birukawa

Division of Biological Sciences, Graduate School of Science

Hokkaido University

Sapporo, Hokkaido 060-0810, Japan

Phone: +81-11-706-4444, Fax: +81-11-706-4448

E-mail: biru-na@sci.hokudai.ac.jp 


\begin{abstract}
Cetaceans are well adapted to their hyperosmotic environment by properly developed osmoregulatory ability. A question here is how they regulate water and mineral balances in marine habitats. In the present study, we determined blood and urine levels of various chemicals involved in osmoregulation, compared them with those in artiodactyls, and characterized the values in the whales. Blood and urine samples obtained from baleen whales of common minke (Balaenoptera acutorostrata), sei (B. borealis), and Bryde's whales (B. brydei), and toothed whales of sperm whales (Physeter macrocephalus) were analyzed for osmolality, major electrolytes, urea, steroid hormones and glucose. The urine osmolality and $\mathrm{Na}^{+}$concentrations in the cetaceans were much higher than those in the cattle. Furthermore, the cetaceans had 5 to 11-fold urea in plasma than the cattle, and 2 to 4 -fold urea in urine. There were no significant difference in the plasma concentrations of corticosteroids between the cetaceans and the cattle. The present results indicate that the osmoregulatory parameters seem to be not affected by the reproductive stage and sex steroid hormones. The concentrations of urea in plasma and urine of the baleen whales were higher than those of the sperm whales, indicating a possibility that their osmoregulatory mechanisms may be correlated to their feeding habits. The present results suggest that cetaceans have unique osmoregulatory mechanisms by which they excrete strongly hypertonic urine to maintain fluid homeostasis in marine habitats.
\end{abstract}

Key Words: osmolality, electrolytes, urea, steroid hormones, cetaceans 


\section{INTRODUCTION}

Marine mammals, whose blood compositions are similar to terrestrial mammals, can survive in seawater, despite the large difference in salinity between their internal fluid and the ambient environment. This fact implies that they should obtain water to maintain the water and mineral homeostasis. There are, however, only a few possibilities to obtain water for marine mammals: extraction from seawater, preformed dietary sources, and metabolic oxidation of food. Occasional seawater drinking is unusual in marine mammals (Elsner, 1999). Their predominant source of water is considered to be their food (Costa, 2002), so that they face different osmoregulatory problems depending on the type of prey that they consume.

The fossil data and genetic information indicated that transition of cetaceans from terrestrial to aquatic life is inferred to be a relatively recent evolutionary event (Graur and Higgins, 1994; Gatesy and O'Leary, 2001; Gingerich et al., 2001). According to the sequence analyses of mitochondrial DNA, the divergence between hippopotamuses and cetaceans was dated to nearly 55 million years ago, while the divergence of basal artiodactyls was dated to 65 million years ago (Arnason et al., 2000). Analyses of retroposon showed that whales, hippopotamuses and ruminants form a monophyletic group (Shimamura et al., 1997; Nikaido et al., 1999; Nikaido et al., 2001a). Extant cetaceans are systematically divided into two suborders: Mysticeti (baleen whales) and Odontoceti (toothed whales), and their divergence was dated to 28-34 million years ago (Nikaido et al., 2001b). Osmoregulation in aquatic ancestors of cetaceans probably relied on physiological mechanisms already present in the kidney of their terrestrial counterparts to maintain the water and electrolyte homeostasis in seawater. In artiodactyls, hippopotamuses live in aquatic environments, whereas a camel is a desert dweller. Comparative analyses of plasma and urine chemicals among cetaceans and artiodactyls that dwell in the different osmotic environments thus yield useful information to understand osmoregulation in cetaceans.

The composition of cetacean blood indicates that the osmotic pressure of whale blood is similar to that of terrestrial mammals (Medway, 1965; Kjeld and Theodorsdottir, 1991; Koopman et al., 1995; Kjeld, 2001; Ortiz, 2001; Reidarson et al., 2001; St. Aubin et al., 2001). Some marine mammals can produce highly concentrated urine (Kjeld and Olafsson, 1987; Beuchat, 1990; Kjeld and Theodorsdottir, 1991; Koopman et al., 1995; Beuchat, 1996; Kjeld, 2001; Ortiz, 2001; St. Aubin et al., 2001), indicating their ability to tolerate drinking of seawater. Recently, using allometry of endogenous creatinine clearance in mammals, 
urine-production rates, average daily krill ingestion, and seawater ingestion of fin (Balaenoptera physalus) and sei whales were estimated (Kjeld, 2003). However, because of their large size and the conservation of cetaceans under treaties and laws, the number of studies which investigated water and electrolyte balance was limited. There are few comparative studies on blood and urine values of chemicals among marine and terrestrial mammals, and also among baleen and toothed whales, which have different feeding habits.

In the present study, fundamental information of blood and urine chemistry was collected to understand the conditions of body fluid compositions in the cetaceans. We determined the values of osmolality, electrolytes $\left(\mathrm{Na}^{+}, \mathrm{K}^{+}, \mathrm{Cl}^{-}, \mathrm{Mg}^{2+}\right.$ and $\left.\mathrm{Ca}^{2+}\right)$ and glucose in blood and urine samples. The same samples were also analyzed to determine the plasma concentrations of steroid hormones, such as aldosterone, cortisol, corticosterone, testosterone, estradiol and progesterone. The values of chemicals in plasma and urine were compared among the cetaceans and the artiodactyls, and also between the baleen and the sperm whales. On the basis of data obtained in the present study, we discussed the possible osmoregulatory mechanisms to maintain such a fluid condition.

\section{MATERIALS AND METHODS}

\section{Samples}

In the present study, samples were obtained by courtesy of several institutions as described below. The treatments of subjects from which plasma and urine were sampled were under the guidelines correspondent with the Guide for Care and Use of Laboratory Animals of Hokkaido University. The sizes and the numbers of animals used in the present study are shown in Table 1.

Whales. Common minke (Balaenoptera acutorostrata), sei (B. borealis), Bryde’s (B. brydei) and sperm whales (Physeter macrocephalus) were captured during the 2002 research cruise of the Japanese Whale Research Program under Special Permit in the western North Pacific-Phase II (JARPN II), carried out from June to September (Fujise et al., 2003). In this research program, baleen and sperm whales have been captured to obtain biological information for the management of the whale population.

Whale carcasses were carried by the sighting and sampling vessels to the research base vessel, Nisshin-maru, where biological measurements and sampling of tissues were carried out. About 5-10 $\mathrm{ml}$ of blood was collected from the flipper or the tip of the upper jaw or 
sometimes the tail vessels of the captured whales into blood collection tubes without anticoagulant immediately after the captured whales were carried to the mother ship. Despite a particular effort to get the fresh postmortem samples as rapid as possible, the delay between death and beginning of blood sampling was about an hour or less. Blood samples were centrifuged at $1500 \mathrm{~g}$ for $10 \mathrm{~min}$ on board within a couple of minutes after collected. Urine samples were collected from the urinary bladder within a few hours. These samples were transferred into $2 \mathrm{ml}$ plastic tubes, and stored at $-80^{\circ} \mathrm{C}$. The volume and contents of four stomachs of the whales were examined on board. Male reproductive status was determined by the testis weight criteria. Common minke whales having one testis weighing $350 \mathrm{~g}$ or over were considered to be sexually mature (Kato, 1986). Similarly, sei whales having one testis weighing 900 g or over and Bryde's whales having a pair of testes weighing $1500 \mathrm{~g}$ or over were considered sexually mature (Nishiwaki et al., 1954; Masaki, 1976). Females were classified into four reproductive groups on the basis of anatomical indicators. They were divided as: sexually immature, mature resting, mature ovulating and mature pregnant distinguished by the presence or absence of a corpus luteum (CL) and/or corpus albicans (CA) in the ovaries (Lockyer, 1984). Some of females were regarded as sexually mature if any CL was found in their ovaries. Female whales with neither CL nor CA in their ovaries were considered immature. The resting group was non-estrous, non-lactating but sexually mature females. Females having ovarian CL without fetus were classified as ovulating females. Pregnancy of females was assessed by the presence of small sized embryos or a fetus in the uterus and a large CL in the ovaries.

Dromedary. Samples of a male dromedary (Camelus dromedarius, 7-year-old, normally maintained) were kindly offered by Dr. Hideki Endo (National Science Museum, Tokyo, Japan) in May 2003. The dromedary was euthanized in deep anesthesia by an intravenous injection of $2 \mathrm{ml} / \mathrm{kg}$ of ketamine/xylazine and $2500 \mathrm{mg}$ of pentobarbital sodium, and then blood was collected from the vein of the side of the nose into blood collection tubes without anticoagulant. Urine samples were collected from the bladder. After centrifugation at 5200 g for $10 \mathrm{~min}$, plasma and urine samples were obtained and stored at $-20^{\circ} \mathrm{C}$.

Bactrian camel. Samples were obtained from a female Bactrian camel (Camelus bactrianus, 11-year-old, $450 \mathrm{~kg}$ ) that was normally maintained in Asahiyama zoo, Hokkaido, Japan in April 2003. Following general anesthesia by an intravenous injection of $850 \mathrm{mg}$ of xylazine and $1860 \mathrm{mg}$ of ketamine, blood was collected from the vein of right hind limb into blood collection tubes treated with EDTA-2K, heparin, and without anticoagulant. Urine was 
collected during urination when the camel was awaking. Plasma sample was obtained after centrifugation at about $1900 \mathrm{~g}$ for $30 \mathrm{~min}$, and stored at $-20^{\circ} \mathrm{C}$ for further analyses. The urine sample was centrifuged for a few minutes and stored at $-20^{\circ} \mathrm{C}$.

Dairy cattle. Dairy cattle (Bos taurus) were maintained in the experimental farms of Hokkaido University. They were given free access to water and regular hay. Blood and urine samples were collected from ten dairy cattle in March 2003. Half of them were lactating cows (3 to 5-year-old, av. $650 \mathrm{~kg}$ ) and the rest was heifer (2-year-old, av. $463 \mathrm{~kg}$ ). Blood samples were collected from the tail-base into blood collection tubes containing EDTA-2K. Plasma samples were collected after centrifugation at about $1900 \mathrm{~g}$ for $30 \mathrm{~min}$, and stored at $-20^{\circ} \mathrm{C}$. Urine samples were collected during urination, centrifuged for a few minutes, and stored at $-20^{\circ} \mathrm{C}$.

\section{Analyses of osmolality and plasma and urine levels of electrolytes, urea and glucose}

Osmolality. Plasma and urine osmolality were measured by a vapor pressure osmometer 5520 (Wescor, Inc., Logan, UT, USA) with fresh $290 \mathrm{mmol} / \mathrm{kg}$ and $1000 \mathrm{mmol} / \mathrm{kg}$ standard solutions. A single Whatman filter paper disc (Wescor, ss-033) was placed in the central depression of the holder by metal forceps, and $10 \mu \mathrm{l}$ of the samples were expelled onto the disc. Saturated discs were rapidly transferred to the vapor pressure osmometer sample holder, and osmolality was determined. All samples were analyzed in duplicate.

Electrolytes. Plasma and urinary concentrations of $\mathrm{Na}^{+}, \mathrm{K}^{+}$and $\mathrm{Cl}^{-}$were determined by an electrolyte analyzer (AVL 9130, AVL-Scientific, Graz, Austria) with electrolyte controls. The detectable ranges were 40-205 mM for $\mathrm{Na}^{+}, 1.5-15 \mathrm{mM}$ for $\mathrm{K}^{+}$, and 50-200 $\mathrm{mM}^{-}$for $\mathrm{Cl}^{-}$ when analyzed by the serum mode. The diluted samples were analyzed according to the manufacture's instruction. The concentrations of $\mathrm{Mg}^{2+}$ and $\mathrm{Ca}^{2+}$ in blood and urine were determined by a Polarized Zeeman Atomic Absorption Spectrophotometer (Z-5300, Z-8000, Hitachi Ltd., Tokyo, Japan). The plasma samples that showed the lower levels of $\mathrm{Na}^{+}$than the detectable limit of an electrolyte analyzer were also analyzed by this spectrophotometer. The diluted samples and standard solutions were analyzed according to the manufacture's instruction. The absorbances of the samples, standard, and control plasma were determined in duplicate.

Urea. Concentrations of urea in blood and urine samples were determined by a Urea N B kit (Wako Pure Chemicals Industries, Ltd., Osaka, Japan) that adopts the Urease-Indophenol method. Color A solution which was prepared fresh daily contained $0.25 \mathrm{M}$ sodium salicylate, $6.7 \mathrm{mM}$ sodium pentacyanonitrosyl ferrate (III) dihydrate and urease solution (19 
$\mathrm{U} / \mathrm{ml}$ ) in $90 \mathrm{mM}$ phosphate buffer, $\mathrm{pH}$ 7.0. Twenty $\mu \mathrm{l}$ of samples, standards, controls, and distilled water as blank were added to $2 \mathrm{ml}$ of Color A solution in 14-ml plastic tubes. The tubes were incubated in $37^{\circ} \mathrm{C}$ water bath for $15 \mathrm{~min}$, and $2 \mathrm{ml}$ of Color B solution was added. They were then incubated in $37^{\circ} \mathrm{C}$ water bath for $10 \mathrm{~min}$. The absorbances of the samples, standards, and control plasma at $595 \mathrm{~nm}$ were measured against the blank tube to determine net absorbance using a microplate reader (MTP-300, Corona Electric Co., Ltd., Hitachinaka, Japan) and a NanoDrop ${ }^{\circledR}$ ND-1000 Spectrophotometer (NanoDrop Technologies, Inc. Rockland, DE, USA). All samples were analyzed in duplicate, and the concentrations of urea in blood and urine samples were estimated.

Glucose. Plasma glucose concentrations were determined using a Glucose CII-Test Wako kit (Wako Pure Chemicals Industries, Ltd.) which adopts the mutarotase-GOD method. Enzyme solution contains mutarotase $(0.13 \mathrm{U} / \mathrm{ml})$, glucose oxidase $(9.0 \mathrm{U} / \mathrm{ml})$, peroxidase $(0.65 \mathrm{U} / \mathrm{ml})$, ascorbate oxidase $(2.7 \mathrm{U} / \mathrm{ml}), 0.5 \mathrm{mM}$ 4-aminoantipyrine, and $5.3 \mathrm{mM}$ phenol in $60 \mathrm{mM}$ phosphate buffer, $\mathrm{pH}$ 7.1. Seven $\mu \mathrm{l}$ of samples, standards, and control plasma were added to $1 \mathrm{ml}$ of enzyme solutions, followed by incubation at $37^{\circ} \mathrm{C}$ for $15 \mathrm{~min}$. The absorbances at $505 \mathrm{~nm}$ of the samples, standards, and control plasma were determined against the blank tube using a NanoDrop ${ }^{\circledR}$ ND-1000 Spectrophotometer. All samples were analyzed in duplicate.

\section{Effects of different anticoagulants}

When we collected blood and urine samples, blood collection tubes without anticoagulant were preferably used to minimize effects of different anticoagulants on the values of determined parameters. In the case of blood sampling from the cattle, however, blood collection tubes treated with EDTA-2K were used, since determination of the plasma levels of peptide hormones were considered of the same blood samples. Effects of different anticoagulants on the levels of chemicals were thus tested in plasma of the Bactrian camel treated with EDTA-2K, heparin, and without anticoagulant. Coefficients of variation (CVs) of electrolyte levels in the plasma samples were 1.3-6.6 \%, except for $\mathrm{K}^{+}$, which were not determined. Nonetheless, different anticoagulants might not seriously affect the results, since the intra-assay CVs of the same plasma samples were sometimes larger than those in the plasma samples treated with different anticoagulants (data not shown). These results indicate that different anticoagulants did not distort the profiles of the plasma electrolyte levels in the present study.

EIA (aldosterone, cortisol, corticosterone, testosterone, estradiol and progesterone) 
Plasma levels of steroid hormones were determined by enzyme immunoassays (EIA) basically as described in the previous studies (Asahina et al., 1995; Onuma et al., 2003). Steroid hormones were extracted from $0.5 \mathrm{ml}$ of plasma samples twice with $3 \mathrm{ml}$ of diethyl ether, evaporated by gentle flow of nitrogen gas, and reconstituted with assay buffer containing $0.2 \%$ bovine serum albumin (BSA) and $0.01 \%$ thimerosal in $0.05 \mathrm{M}$ borate buffer, pH 7.8. Microtiter plates (MS-8496F, Sumitomo Bakelite Co. Ltd., Tokyo, Japan) were coated with $15 \mu \mathrm{g} / \mathrm{ml}$ anti-rabbit IgG (ICN Pharmaceuticals, Inc., Aurora, OH, USA), $0.05 \mathrm{M}$ carbonate buffer, $\mathrm{pH}$ 9.7, and further coated with blocking solution containing $0.1 \%$ BSA and 3\% sucrose in $0.05 \mathrm{M}$ phosphate buffer, $\mathrm{pH}$ 7.4. The standards and samples were incubated with anti-steroid antiserum and HRP-labeled steroid (FKA 428-E, FKA 427 for aldosterone, FKA 404-E, FKA 403 for cortisol, FKA 420-E, FKA-419 for corticosterone, FKA 102-E, FKA 101 for testosterone, FKA 236-E, FKA 235 for estradiol, and FKA 302-E, FKA 301 for progesterone, Cosmo Bio Co. Ltd, Tokyo, Japan) at $4^{\circ} \mathrm{C}$ overnight. After washing with $0.9 \%$ $\mathrm{NaCl}$, a substrate solution $\left(0.5 \mathrm{mg} / \mathrm{ml}\right.$ o-phenylenediamine, $0.01 \% \mathrm{H}_{2} \mathrm{O}_{2}$ in $0.2 \mathrm{M}$ citrate buffer, $\mathrm{pH}$ 4.5) was added and incubated at room temperature for $30 \mathrm{~min}$. The reaction was stopped by addition of $0.6 \mathrm{~N} \mathrm{H}_{2} \mathrm{SO}_{4}$ and the absorbance at $492 \mathrm{~nm}$ was measured with a microplate reader (MTP-300, Corona Electric Co. Ltd.). All samples were analyzed in duplicate.

In aldosterone assay, corticosterone showed cross-reactivity of $0.01 \%$ and cortisol less than $0.002 \%$. In the cortisol assay, 11-deoxycortisol showed cross-reactivity of $11.5 \%$, cortisone $4.0 \%$, corticosterone $2.0 \%$, and other structurally related steroids $0.2 \%$ or less. In corticosterone assay, DOC showed cross-reactivity of $8.0 \%$, progesterone $2.1 \%$, and other structurally related steroids $0.2 \%$ or less. In testosterone assay, $5 \alpha$-dihydrotestosterone showed cross-reactivity of $7.3 \%$, androsterone $2.1 \%$, 4 -androstenedione $0.82 \%$, and other steroids $0.15 \%$ or less. In estradiol assay, estradiol-3-glucuronide showed cross-reactivity of $56.3 \%$, estrone-3-sulfate $26.8 \%$, estrone-3-glucuronide $1.2 \%$, estrone-3-sulfate $0.86 \%$, estrone $0.8 \%$, estriol $0.5 \%$, and testosterone $0.05 \%$. In progesterone assay, 5a-pregnanedione showed cross-reactivity of $12.5 \%, 11 \mathrm{a}-\mathrm{OH}$-progesterone $5.3 \%$, pregnenolone $2.0 \%$, and other steroids less than $0.2 \%$.

\section{Validation of EIA}

The detection limit of the assay was $300 \mathrm{pg} / \mathrm{ml}$, expect for testosterone $(30 \mathrm{pg} / \mathrm{ml})$ and estradiol $(10 \mathrm{pg} / \mathrm{ml})$. A recovery of each hormone after extraction was checked by addition of standard solution to the mixed and pooled plasma samples of several cetacean species and 
cattle. The recovery of each hormone was 78.9-126.8\%. Both intra- and inter-assay CVs were within $15 \%$ for each hormone assay. Parallelisms between the extracted steroid hormones and the standard solutions were also examined by the parallel line assay. Serial dilution of the samples showed parallelism to the standard curves (data not shown). These results indicate that the present assay system is appropriate to determine the plasma levels of steroid hormones in the cetaceans, camels and cattle.

\section{Statistical analyses}

Values were presented as means \pm standard error of the means. One-way ANOVA followed by Tukey's test was applied for differences among species. Comparisons between gender were performed by Student's $t$-test. Correlations between the biological and chemical values, the plasma levels of steroid hormones, and time lag from death to beginning of blood and urine sampling were determined by Pearson's correlation coefficient. Because of difficulty to obtain sufficient numbers of samples from sperm whales, dromedary and Bactrian camel, we could not perform statistical analyses to detect the significant differences among them. In the comparison of the plasma concentrations of sex steroid hormones among different reproductive status in the cetaceans, we could not apply statistical analyses for the same reason. The values of lactating cow and heifer were combined, since the significant differences between them were not detected in most parameters.

\section{RESULTS}

The plasma osmolality in the cetaceans was slightly higher than that in the cattle, whereas the cetacean urine osmolality was obviously higher (Fig. 1). The concentrations of $\mathrm{Na}^{+}$and $\mathrm{Cl}^{-}$in plasma and urine also showed similar tendency (Tables 2, 3, Fig. 2). The differences in the osmolality and the levels of most electrolytes between the cetaceans and the artiodactyls were greater in urine than in plasma (Tables 2, 3 and Fig. 1-3). The plasma concentrations of urea in the cetaceans were 5 to 11-fold those in the cattle, and the urine concentrations were 2 to 4-fold (Fig. 4). Although the plasma concentrations of aldosterone in most of the cetaceans were higher than those in the camels and the cattle (Fig. 5), there were no significant differences in the levels of corticosteroids between the cetaceans and the cattle (Fig. 6). The baleen whales showed higher concentrations of most electrolytes and urea in plasma and urine than the sperm whales (Tables 2, 3 and Fig. 1-4). Some positive and negative correlations of variables showing physiologically interesting are listed in Table 5. 


\section{Osmolality (Fig. 1)}

The osmolality of urine was 3 to 4 -fold that of plasma in all species. The female baleen whales showed slightly but significantly higher plasma osmolality than the cattle, and the osmolality of cetacean urine was obviously higher than that of the cattle urine. In the cetaceans, the osmolalities of plasma and urine in the baleen whales were higher than those in the sperm whales. The osmolalities of plasma and urine in the whales showed positive correlations with the plasma and urine levels of most electrolytes, respectively $(p<0.05$, Table 5).

\section{Electrolytes}

$\mathrm{Na}^{+}$(Fig. 2) and $\mathrm{Cl}^{-}$(Tables 2, 3). The plasma levels of $\mathrm{Na}^{+}$in the baleen whales were 1.2-fold those in the cattle, whereas the urinary levels of $\mathrm{Na}^{+}$in the baleen whales were about 7-fold those in the cattle. The ratio of urine $\mathrm{Cl}^{-}$levels between the baleen whales and the cattle was also higher than that in the plasma. In the cetaceans, the plasma and urine concentrations of $\mathrm{Na}^{+}$in the baleen whales were higher than those in the sperm whales, whereas the plasma and urine concentrations of $\mathrm{Cl}^{-}$in the sperm whales were similar to those in the baleen whales.

$\mathbf{K}^{+}$(Fig. 3). The plasma concentrations of $\mathrm{K}^{+}$in the cattle could not be determined as blood samples from the cattle were treated with EDTA-2K. Plasma levels of $\mathrm{K}^{+}$in the cetaceans were similar to those in the camels. Urinary levels of $\mathrm{K}^{+}$in the cattle were much higher than those in the other animals. Significant correlations were found between the time lag from death to sampling and the plasma levels of $\mathrm{K}^{+}$in the male minke and Bryde's whales $(\mathrm{p}<0.05$, Table 2, 3, Fig. 1-4

$\mathbf{M g}^{2+}$ and $\mathrm{Ca}^{2+}$ (Tables 2, 3). Although significant differences in the levels of plasma $\mathrm{Mg}^{2+}$ among species were not detected, the male Bryde's whales had higher levels of plasma $\mathrm{Mg}^{2+}$ than the females $(\mathrm{p}<0.05)$. Sexual difference in the plasma $\mathrm{Mg}^{2+}$ levels was found only in this species. In the sei whales, the plasma levels of $\mathrm{Ca}^{2+}$ in the males were significantly higher than those in the females $(\mathrm{p}<0.05)$. The urinary levels of $\mathrm{Ca}^{2+}$ in the cattle were much higher than those in the other species.

\section{Urea (Fig. 4)}

The plasma concentrations of urea in the cetaceans were 5 to 11 -fold those in the cattle, and the urine concentrations were 2 to 4 -fold. The levels of urinary urea in the camels were similar to those in the cetaceans. The Bryde's whales showed higher plasma levels of urea than the other baleen whales and the sperm whales. The concentrations of urea in plasma 
and urine in the baleen whales were $50-90 \%$ higher than those in the sperm whales.

\section{Steroid hormones and glucose}

Aldosterone (Fig. 5), cortisol, corticosterone (Fig. 6) and glucose (Table 2). The plasma levels of aldosterone in the dromedary and most of the cattle could not be determined, because they were lower than the detectable limit (300 pg/ml), whereas those in the cetaceans could be determined. Although the plasma concentrations of aldosterone in most of the cetaceans were higher than those in the camels and the cattle, there were no significant differences in the levels of corticosteroids between the cetaceans and the cattle. There was a negative correlation between the urinary levels of $\mathrm{Na}^{+}$and aldosterone in the female sei whales ( $<<0.05$, Table 5). The camels showed much higher levels of cortisol, corticosterone and glucose than the cetaceans and the cattle. Positive correlations between corticosteroids were demonstrated in the male minke and sei whales $(\mathrm{p}<0.05$, Table 5$)$. There was a significant correlation between the plasma levels of corticosterone and glucose in the female Bryde's whales ( $<<0.05$, Table 5).

Testosterone, estradiol and progesterone (Table 4). In the common minke and Bryde's

Fig. 5-6
wilites, ule ıevels or testusterone in the mature animals were higher than those in the immature whales. All female sei whales were pregnant, and the pregnant whales tended to have higher levels of progesterone than the other reproductive status in all species. There were no significant differences between the lactating cow and the heifer in the levels of estradiol and progesterone. There were positive correlations between body length or body weight and the plasma levels of progesterone in the female minke whales $(p<0.05$, data not shown), however, no correlations were found between the high values of steroid hormones and the plasma concentrations of electrolytes.

\section{DISCUSSION}

In the present study, we showed plasma and urine chemistry in cetaceans and artiodactyls. We found that the cetaceans concentrate $\mathrm{Na}^{+}$and urea to excrete highly concentrated urine than the artiodactyls. There were no significant difference in the plasma concentrations of corticosteroids between the cetaceans and the cattle. The baleen whales showed higher concentrations of $\mathrm{Na}^{+}$and urea than the sperm whales in plasma and urine.

\section{Effects of capture}

The present results in the whales were obtained from the samples postmortally collected 
and the time lag from death to beginning of blood and urine collection was about one hour. According to the previous study in dogs (Schoning and Strafuss, 1980), postmortem blood $\mathrm{Na}^{+}$and $\mathrm{Cl}^{-}$values decreased slightly within 3 hours after death, whereas $\mathrm{K}^{+}$levels increased relatively fast with time. We consider that the present sampling protocol was not serious to the plasma and urinary levels of most electrolytes, since the length of time lag between death and sampling correlated only with the plasma levels of $\mathrm{K}^{+}$in the male whales $(\mathrm{p}<0.05$, Table 5). We were also afraid of a possibility of a contamination of samples with seawater, despite careful sampling of blood and urine. It was proposed that the levels higher than $4.5 \mathrm{mM}$ of plasma $\mathrm{Mg}^{2+}$ indicated more than 5\% contamination (Kjeld, 1987). In the present study, the plasma levels of $\mathrm{Mg}^{2+}$ in a few plasma samples were higher than $4.5 \mathrm{mM}$, however, the levels of other chemicals were similar to those in the other samples. Thus, we consider that the plasma samples in the present study were not seriously affected by artifacts and seawater contamination.

\section{Osmolality and electrolytes}

The plasma and urine levels of electrolytes in the whales reported here, except for $\mathrm{K}^{+}$, were consistent with those in the previous reports on the captive, free-ranging and rehabilitating cetaceans (Medway, 1965; Kjeld, 1987; Kjeld and Theodorsdottir, 1991; Koopman et al., 1995; Ortiz and Worthy, 2000; Kjeld, 2001; Ortiz, 2001; Reidarson et al., 2001; St. Aubin et al., 2001; Kjeld, 2003). Hence, the values in the present whale samples were considered to be relatively close to those of living whales. The values in the cattle, except for the much higher values of urinary $\mathrm{K}^{+}$, were also almost the same with those reported previously (Kaneko et al., 1997). In contrast, the plasma levels of $\mathrm{K}^{+}$in the whales were slightly higher than those samples taken from free-ranging bottlenose dolphins (Tursiops truncatus), harbor porpoises (Phocoena phocoena), and the rehabilitating California gray whale calf (Eschrichtius robustsu) (Medway, 1965; Koopman et al., 1995; Ortiz and Worthy, 2000; Reidarson et al., 2001), indicating postmortem increase of the plasma values of $\mathrm{K}^{+}$in the whales. In the present results, the urine values of osmolality, $\mathrm{Na}^{+}$, and $\mathrm{Cl}^{-}$in the female baleen whales were significantly higher than those in the cattle $(p<0.05)$, indicating that increased excretion of these electrolytes should be a critical factor for cetaceans to regulate the levels of body salts to adapt for their marine environment.

\section{Urea}

Urea plays a key role in the urine-concentrating mechanism in mammals (Sands, 2002). In the inner medullary collecting duct, a gradient of urea is established for passive $\mathrm{NaCl}$ 
absorption in the absence of an osmotic gradient. There may be multiple mechanisms by which vasopressin regulates the different urea transporter proteins and mRNA isoforms to reabsorb and recycle urea in the kidney. The plasma concentrations of urea in the baleen whales were higher than those in the sperm whales in the present study, and also in some captive odontocetes and beluga whales (Delphinapterus leucas) (Malvin and Rayner, 1968; St. Aubin et al., 2001). Furthermore, the baleen whales showed higher concentrations of urea in both plasma and urine than the cattle and camels in this study, and other land mammals (Kaneko et al., 1997). The present study suggest that the cetaceans could maintain their body fluid to utilize urea in their kidney and that different actions of urea transporters between marine and terrestrial mammals, but there is only one report which investigated the function of urea transporters in cetaceans (Janech et al., 2002).

\section{Adrenocortical hormones}

Aldosterone promotes $\mathrm{Na}^{+}$absorption and $\mathrm{K}^{+}$secretion across the renal distal tubule-collecting duct system in mammals. The plasma levels of aldosterone in the whales were higher than those in the other whales previously reported (Ortiz and Worthy, 2000; Kjeld, 2001; St. Aubin, 2001), so that the values of aldosterone may be valuated slightly higher in our present assays. In the present study, the cetaceans showed the higher levels of plasma aldosterone than the artiodactyls. Nevertheless, only in the female sei whales, a negative correlation was found between the plasma levels of aldosterone and the urinary concentrations of $\mathrm{Na}^{+}$(Table 5). The high value of plasma aldosterone in the male sperm whales in Fig. 5 was due to abnormal values of one male sperm whale, which showed the higher values of most steroid hormones, however, it did not show the abnormal values of any other plasma chemicals.

Anesthesia with ketamine and xylazine has little effect on glucocorticoid levels in rabbit within 1 hour after treatment (Illera et al., 2000). Since our blood samples were collected from the anesthetized camels within 1 hour after treatment, we consider that the levels of their plasma glucocorticoid were not affected by anesthesia but adrenocorticotropin-induced stimulation by stress response. In contrast, the plasma levels of corticosteroids and glucose in the whales and the cattle correspond with the reported values (Kaneko et al., 1997; St. Aubin, 2001) respectively, and the plasma levels of corticosteroids in the cetaceans were similar to those in the cattle, indicating that they were seem to be not affected by stress response. In Indo-Pacific bottlenose dolphin and killer whales (Orcinus orca), diural changes in the cortisol levels were exhibited as diurnal terrestrial mammals (Suzuki et al., 
2003), however, in this study the cetaceans did not show any daily pattern of plasma cortisol levels in relation to the time of day (data not shown) as Kjeld showed in the fin whales (2001). There were no significant differences in the plasma concentrations of corticosteroids between the cetaceans and the cattle, suggesting that corticosteroids are not important for osmoregulation in cetaceans.

\section{Sex steroid hormones}

In the common minke and Bryde's whales, the levels of testosterone in the immature animals were lower than those in the mature whales and similar to those in the common and southern minke, Bryde's, and sei whales in feeding season reported previously (Yoshioka and Fujise, 1992; Suzuki et al., 2001; Kjeld et al., 2003; Kjeld et al., 2004; Watanabe et al., 2004). There were no correlations between the plasma levels of testosterone and the plasma and urine values of osmolality in the male whales.

The present study showed that the pregnant whales had the higher levels of progesterone than the animals of other reproductive status. These high levels in the pregnants were almost similar to those in common and southern minke whales reported previously (Yoshioka et al., 1990; Yoshioka and Fujise, 1992; Iga et al., 1996; Suzuki et al., 2001; Kjeld et al., 2003; Kjeld et al., 2004; Muranishi et al., 2004). It has been shown that pregnancy is characterized by an increase in extracellular fluid, plasma, and blood volume in different mammalian species (Phippard et al., 1986; Schrier and Briner, 1991), and that vasopressin response to an osmotic challenge is affected by sex steroid hormones (Sladek et al., 2000). However, there were no positive correlations between the high levels of plasma sex steroid hormones and the plasma and urine values of osmolality in the pregnant whales. The female minke whales showed significantly higher levels of most steroid hormones than the males and sometimes than the females of other whale species $(\mathrm{p}<0.05)$, but no correlations were found between the high values of steroid hormones and the plasma concentrations of electrolytes in the female minke whales. The present results indicate that the osmoregulatory parameters seem to be not affected by the reproductive stage and sex steroid hormones.

\section{The effects of different feeding habit}

Since marine mammals appear to obtain source of water from their food (Costa, 2002), and the ratio of water to electrolytes is quite different between vertebrate and invertebrate prey, marine mammals face different osmoregulatory problems depending on the type of prey that they consume. Typically baleen whales feed on zooplankton, mainly euphausiids or copepod since they are enriched with essential amino acids, but their major food items are 
specialized with area. According to the report of the present cruise (Fujise et al., 2003), most common minke and sei whales fed on krill, copepod, and anchovies, whereas the Bryde's whale took anchovies, and the sperm whales mainly had squids.

We found that the baleen whales had the higher concentrations of $\mathrm{Na}^{+}$and urea in plasma and urine than the sperm whales. The levels found in the sperm whales are similar to those found in the other toothed whales like bottlenose dolphin and beluga (Malvin and Rayner, 1968; St. Aubin et al., 2001), which feed mainly on fish. As mentioned earlier, the predominant source of water in marine mammals is considered to be their food (Costa, 2002) and then osmoregulatory mechanism could be influenced by the type of prey they consume. Therefore the differences in the concentrations of $\mathrm{Na}^{+}$and urea between the baleen and the sperm whales reported in this study can be explained by their different feeding habits. Further works that consider in more detail the different feeding habits between baleen and toothed whales could assist in understanding the osmoregulatory mechanisms in cetaceans.

\section{Possible mechanisms of cetacean osmoregulation}

Vasopressin, aldosterone, urea transporter and aquaporin are important to maintain water and electrolytes homeostasis in the mammalian kidney. The present study indicated a possibility of more efficient actions of urea transporters in cetacean than that in terrestrial mammals, since the whales could maintain high levels of urea in plasma and excrete concentrated urea in urine. Function of some types of urea transporters is regulated by vasopressin for urea reabsorption and also water reabsorption (Sands, 2002). The high levels of electrolytes and urea in the cetacean urine indicated that antidiuretic action, probably of vasopressin, is important for production of hypertonic urine. Studies on the function of vasopressin and urea transporter will help us to understand the mechanisms of cetacean osmoregulation.

\section{Conclusion}

The present study showed that the cetaceans conserve their body water by producing more concentrated urine than the terrestrial mammals. Although the plasma concentrations of aldosterone in the cetaceans were higher than those of the cattle, there were no significant difference in the plasma concentrations of corticosteroids between the cetaceans and the cattle, suggesting that corticosteroids are not important for osmoregulation in the cetaceans. Instead, vasopressin may have important roles to retain water in the cetacean kidney as shown in terrestrial mammals. Urea transporters in the kidney also appear to offer effective mechanisms to produce hypertonic urine. Cetaceans have unique osmoregulatory 
mechanisms, which are correlated to their feeding habits, to excrete hypertonic urine and maintain fluid homeostasis to adapt seawater.

\section{ACKNOWLEDGMENTS}

We wish to express our sincere gratitude to the captain and all cruise of Nisshin-maru for their help in sampling efforts. We extend our gratitude to Dr. Masao Kosuge, Dr. Daisuke, Fukui, and Dr. Gen Bando, Asahiyama zoo, Hokkaido and Dr. Hideki Endo, National Science Museum, Tokyo, who granted us the opportunity to collect the samples from the camels. We are grateful to Professor Yoshio Takei, Professor Susumu Hyodo and all the members and staff of Ocean Research Institute, University of Tokyo, for their help in analyzing samples. We are also grateful to Professor Shinichiro Noriki and Mr. Nobuyuki Takahashi, Laboratory of Marine and Atmospheric Geochemistry, Graduate School of Environmental Earth Science, Hokkaido University, for their help to analyze the chemical values in blood and urine. 


\section{REFERENCES}

Arnason U, Gullberg A, Gretarsdottir S, Ursing B, Janke A (2000) The mitochondrial genome of the sperm whale and a new molecular reference for estimating eutherian divergence dates. J Mol Evol 50: 569-578

Asahina K, Kambegawa A, Higashi T (1995) Development of a microtiter plate enzyme-linked-immunosorbent-assay for 17-alpha, 20-beta-21-trihydroxy-4-pregnen-3-one, a teleost gonadal-steroid. Fish Sci 61: 491-494

Beuchat CA (1990) Body size, medullary thickness, and urine concentrating ability in mammals. Am J Physiol 258: R298-R308

Beuchat CA (1996) Structure and concentrating ability of the mammalian kidney: correlations with habit. Am J Physiol 271: R157-R179

Costa DP (2002) Osmoregulation. In "Encyclopedia of Marine Mammals" Ed by WF Perrin, B Wursig, JGM Thewissen, WF Perrin, BG Wursig, Academic Press, San Diego, pp 837-842

Elsner R (1999) Living in water: solutions to physiological problems. In "Biology of Marine Mammals" Ed by SAR Reynolds III, Smithonian Institution Press, Washington and London, pp 73-116

Fujise Y, Tamura T, Bando T, Yasunaga G, Konishi K, Murase H, Yoshida T, Itoh S, Ogawa R, Oka T, Sasaki T, Fukutome K, Isoda T, Birukawa N, Horii N, Zharikov KA, Park KJ, Tohyama D, Kawahara S (2003) Cruise report of the Japanese Whale Research Program under special permit in the western North Pacific-Phase II (JARPN II) in 2002 (part I) Offshore component -. Paper SC/55/O7 submitted to the $55^{\text {th }}$ IWC Scientific Committee Meeting (Available from the IWC Secretariat), 202 pp

Gatesy J, O'Leary MA (2001) Deciphering whale origins with molecules and fossils. Trends Ecol Evol 16: 562-570

Gingerich PD, Haq M, Zalmout IS, Khan IH, Malkani MS (2001) Origin of whales from early artiodactyls: hands and feet of Eocene Protocetidae from Pakistan. Science 293: 2239-2242

Graur D, Higgins DG (1994) Molecular evidence for the inclusion of cetaceans within the order Artiodactyla. Mol Biol Evol 11: 357-364 
Iga K, Fukui Y, Miyamoto A, Ishikawa H, Ohsumi S (1996) Endocrinological observations of female minke whales (Balaenoptera acutorostrata). Mar Mammal Sci 12: 296-301

Illera JC, Gil AG, Silvan G, Illera M (2000) The effects of different anaesthetic treatments on the adreno-cortical functions and glucose levels in NZW rabbits. J Physiol Biochem 56: 329-336

Janech MG, Chen R, Klein J, Nowak MW, McFee W, Paul RV, Fitzgibbon WR, Ploth DW (2002) Molecular and functional characterization of a urea transporter from the kidney of a short-finned pilot whale. Am J Physiol Regul Integr Comp Physiol 282: R1490-R1500

Kaneko JJ, Harvey JW, Bruss ML (1997) Clinical Biochemistry of Domestic Animals. 5th ed, Academic Press, San Diego

Kato H (1986) Studies on the yearly changes in biological parameters and population dynamics in southern minke whales. Ph.D. Thesis, Graduate School of Fisheries Science, Hokkaido University, Sapporo (In Japanese)

Kjeld M, Olafsson I (1987) Some biochemical parameters in blood and urine of fin whales (Balaenoptera physalus). Isr J Vet Med 43: 117-121

Kjeld M, Theodorsdottir A (1991) Some electrolytes, hormones and other substances in the blood of fin whales of the coast of Iceland. Natturufrasingurinn 60: 147-154

Kjeld M (2001) Concentrations of electrolytes, hormones, and other constituents in fresh postmortem blood and urine of fin whales (Balaenoptera physalus). Can J Zool 79: 438-446

Kjeld M (2003) Salt and water balance of modern baleen whales: rate of urine production and food intake. Can J Zool 81: 606-616

Kjeld M, Vikingsson GA, Alfredsson A, Olafsson O, Arnason A (2003) Sex hormone concentrations in the blood of sei whales (Balaenoptera borealis) off Iceland. J Cetacean Res Manage 5: 233-240

Kjeld M, Alfredsson A, Olafsson O, Tryland M, Christensen I, Stuen S, Arnason A (2004) Changes in blood testosterone and progesterone concentrations of the North Atlantic minke whale (Balaenoptera acutorostrata) during the feeding season. Can J Fish Aquat Sci 61: 230-237 
Koopman HN, Westgate AJ, Read AJ, Gaskin DE (1995) Blood chemistry of wild harbor porpoises Phocoena phocoena (L.). $\quad$ Mar Mammal Sci 11: 123-135

Lockyer C (1984) Review of baleen whales (Mysticeti) reproduction and implications for management. In "Reproduction of Whales, Dolphin and Porpoise" Ed by WF Perrin, RL Brownell Jr., DP DeMaster, Rep Int Whaling Comm Spec 6: 26-49

Malvin RL, Rayner M (1968) Renal function and blood chemistry in cetacea. Am J Physiol 214: $187-191$

Masaki Y (1976) Biological studies on the north pacific sei whale. Bull Far seas Fish Res Lab 14: 1-103

Medway W (1965) Blood chemistry of the bottlenose dolphin (Tursiops truncatus). Am J Physiol 209: 169-172

Muranishi Y, Sasaki M, Hayashi K, Abe N, Fujihira T, Ishikawa H, Ohsumi S, Miyamoto A, Fukui Y (2004) Relationship between the appearance of preantral follicles in the fetal ovary of Antarctic minke whales (Balaenoptera bonaerensis) and hormone concentrations in the fetal heart, umbilical cord and maternal blood. Zygote 12: $125-132$

Nikaido M, Rooney AP, Okada N (1999) Phylogenetic relationships among cetartiodactyls based on insertions of short and long interpersed elements: hippopotamuses are the closest extant relatives of whales. Proc Natl Acad Sci U S A 96: 10261-10266

Nikaido M, Matsuno F, Abe H, Shimamura M, Hamilton H, Matsubayashi H, Okada N (2001a) Evolution of CHR-2 SINEs in cetartiodactyl genomes: possible evidence for the monophyletic origin of toothed whales. Mamm Genome 12: 909-915

Nikaido M, Matsuno F, Hamilton H, Brownell RL, Jr., Cao Y, Ding W, Zuoyan Z, Shedlock AM, Fordyce RE, Hasegawa M, Okada N (2001b) Retroposon analysis of major cetacean lineages: the monophyly of toothed whales and the paraphyly of river dolphins. Proc Natl Acad Sci U S A 98: 7384-7389

Nishiwaki M, Hibiya T, Kimura S (1954) On the sexual maturity of the sei whale of the Bonin waters. Sci Rep Whales Res Inst 9: 165-178

Onuma T, Higashi Y, Ando H, Ban M, Ueda H, Urano A (2003) Year-to-year differences in plasma levels of steroid hormones in pre-spawning chum salmon. Gen Comp 
Endocrinol 133: 199-215

Ortiz RM, Worthy GA (2000) Effects of capture on adrenal steroid and vasopressin concentrations in free-ranging bottlenose dolphins (Tursiops truncatus). Comp Biochem Physiol A Mol Integr Physiol 125: 317-324

Ortiz RM (2001) Osmoregulation in marine mammals. J Exp Biol 204: 1831-1844 Phippard AF, Horvath JS, Glynn EM, Garner MG, Fletcher PJ, Duggin GG, Tiller DJ (1986) Circulatory adaptation to pregnancy-serial studies of haemodynamics, blood volume, renin and aldosterone in the baboon (Papio hamadryas). J Hypertens 4: 773-779

Reidarson TH, McBain JF, Yochem PK (2001) Medical and nutritional aspects of a rehabilitating California gray whale calf. Aquatic Mammals 27: 215-221

Sands JM (2002) Molecular approaches to urea transporters. J Am Soc Nephrol 13: 2795-2806

Schoning P, Strafuss AC (1980) Determining time of death of a dog by analyzing blood, cerebrospinal-fluid, and vitreous-humor collected at postmortem. Am J Vet Res 41: 955-957

Schrier RW, Briner VA (1991) Peripheral arterial vasodilation hypothesis of sodium and water retention in pregnancy: implications for pathogenesis of preeclampsia-eclampsia. Obstet Gynecol 77: 632-639

Shimamura M, Yasue H, Ohshima K, Abe H, Kato H, Kishiro T, Goto M, Munechika I, Okada N (1997) Molecular evidence from retroposons that whales form a clade within even-toed ungulates. Nature 388: 666-670

Sladek CD, Swenson KL, Kapoor R, Sidorowicz HE (2000) The role of steroid hormones in the regulation of vasopressin and oxytocin release and mRNA expression in hypothalamo-neurohypophysial explants from the rat. Exp Physiol 85 Spec: 171S-177S St. Aubin DJ (2001) Endocrinology. In "CRC Handbook of Marine Mammal Medicine" Ed by LA Dierauf, FMD Gulland, CRC press, Boca Raton, pp 165-192

St. Aubin DJ, Deguise S, Richard PR, Smith TG, Geraci JR (2001) Hematology and plasma chemistry as indicators of health and ecological status in beluga whales, Delphinapterus leucas. Arctic 54: 317-331 
Suzuki T, Mogoe T, Asada M, Miyamoto A, Tetsuka M, Ishikawa H, Ohsumi S, Fukui Y (2001) Plasma and pituitary concentrations of gonadotropins (FSH and LH) in minke whales (Balaenoptera acutorostrata) during the feeding season. Theriogenology 55: $1127-1141$

Suzuki M, Uchida S, Ueda K, Tobayama T, Katsumata E, Yoshioka M, Aida K (2003) Diurnal and annual changes in serum cortisol concentrations in Indo-Pacific bottlenose dolphins Tursiops aduncus and killer whales Orcinus orca. Gen Comp Endocrinol 132(3): 427-433

Yosioka M, Fujise Y, Kato H, Aida K (1990) Serum progesterone levels in southern minke whales by reproductive status. Document SC/42/SHMi33 presented to the $42^{\text {nd }}$ IWC Scientific Committee, 10pp

Yosioka M, Fujise Y (1992) Serum testosterone and progesterone levels in southern minke whales (Balaenoptera acutorostrata). Document SC/44/SHB13 presented to the $44^{\text {th }}$ IWC Scientific Committee, 4pp

Watanabe H, Mogoe T, Asada M, Hayashi K, Fujise Y, Ishikawa H, Ohsumi S, Miyamoto A, Fukui Y (2004) Relationship between serum sex hormone concentrations and histology of seminiferous tubules of captured baleen whales in the Western North Pacific during the feeding season. J Reprod Dev 50: 419-427 
Table 1. The numbers, means \pm SE of body length (BL) and body weight (BW) of animals used in the present study.

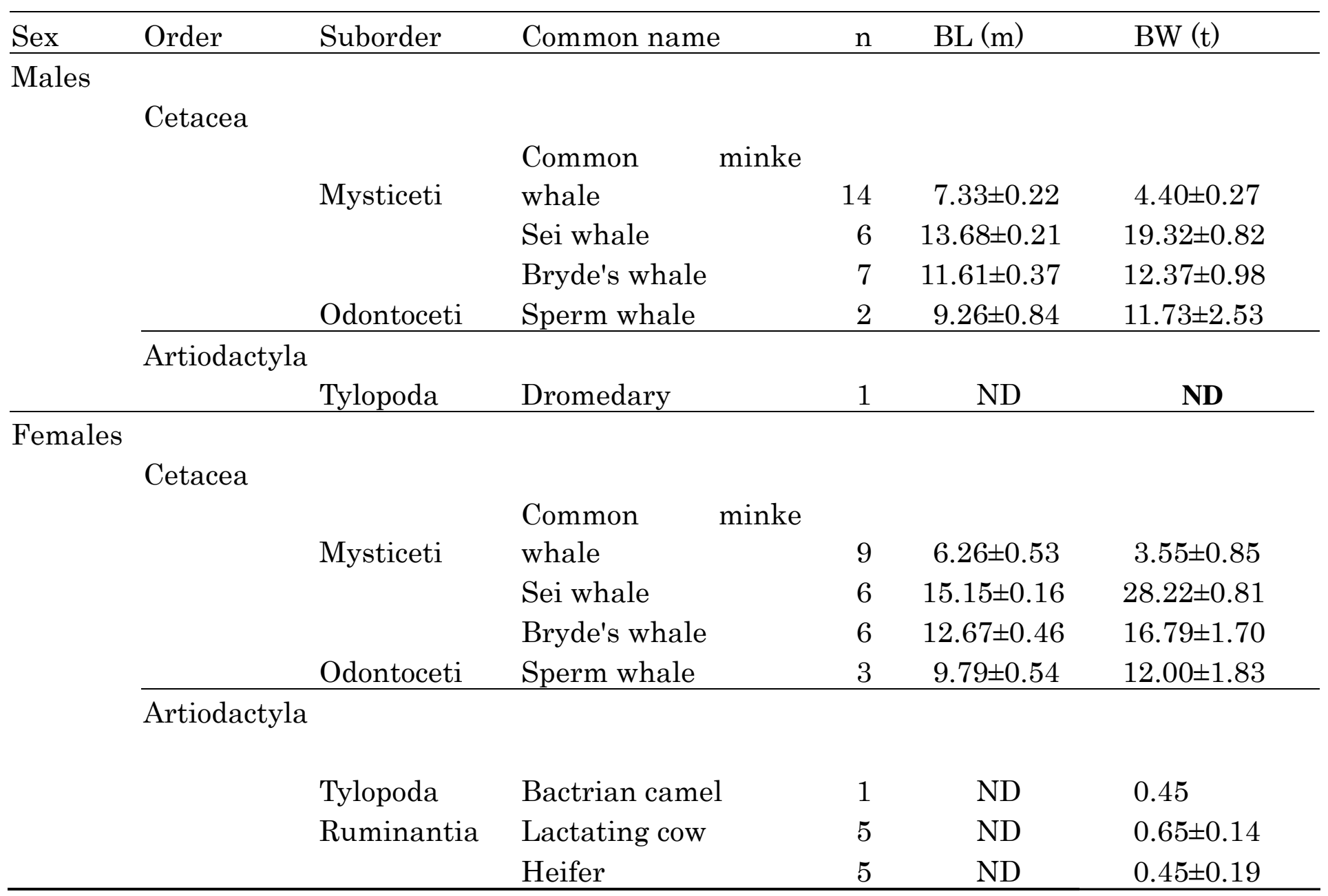

ND: not determined. 
Table 2. Concentrations of chemicals in plasma (means $\pm \mathrm{SE}$ ).

\begin{tabular}{|c|c|c|c|c|c|c|}
\hline Sex & $\begin{array}{l}\text { Order } \\
\text { Common name }\end{array}$ & $\mathrm{n}$ & $\begin{array}{l}\mathrm{Cl}^{-} \\
(\mathrm{mM})\end{array}$ & $\begin{array}{l}\mathrm{Mg}^{2+} \\
(\mathrm{mM})\end{array}$ & $\begin{array}{l}\mathrm{Ca}^{2+} \\
(\mathrm{mM}) \\
\end{array}$ & $\begin{array}{l}\text { Glucose } \\
(\mathrm{mM})\end{array}$ \\
\hline \multicolumn{7}{|c|}{ Males } \\
\hline \multicolumn{7}{|c|}{ Cetacea } \\
\hline & Common minke whale & 14 & $112.2 \pm 4.1$ & $2.0 \pm 0.3$ & $3.3 \pm 0.1$ & $5.5 \pm 0.8$ \\
\hline & Sei whale & 6 & $107.9 \pm 3.1$ & $2.1 \pm 0.2$ & $3.6 \pm 0.1^{* *}$ & $8.3 \pm 0.9$ \\
\hline & Bryde's whale & 7 & $128.0 \pm 10.7$ & $4.5 \pm 2.0^{*}$ & $3.6 \pm 0.2$ & $6.2 \pm 1.1$ \\
\hline & Sperm whale & 2 & $125.3 \pm 0.3$ & $2.2 \pm 0.3$ & $3.0 \pm 0.2$ & $4.4 \pm 1.2$ \\
\hline \multicolumn{7}{|c|}{ Artiodactyla } \\
\hline & Dromedary & 1 & 109.0 & 1.3 & 2.5 & 18.1 \\
\hline
\end{tabular}

Femal

es

Cetacea

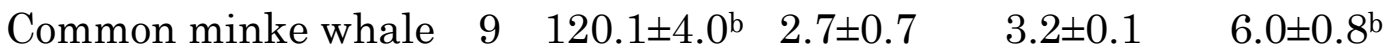

$5.4 \pm 0.4^{\mathrm{a}}$

Sei whale

$\begin{array}{lllll}6 & 109.3 \pm 5.1^{\mathrm{b}} & 2.5 \pm 0.9 & 3.4 \pm 0.2 \quad \mathrm{~b}\end{array}$

Bryde's whale

$\begin{array}{lllll}6 & 111.1 \pm 2.1^{\mathrm{b}} & 1.9 \pm 0.3 & 3.5 \pm 0.1 & 6.2 \pm 0.8^{\mathrm{b}}\end{array}$

Sperm whale

$\begin{array}{lllll}3 & 119.3 \pm 2.7 & 1.7 \pm 0.2 & 2.6 \pm 0.1 & 3.3 \pm 0.2\end{array}$

Artiodactyla

\begin{tabular}{lcllll} 
Bactrian camel & 1 & 105.0 & 1.1 & 2.9 & 11.2 \\
Cattle & 10 & $102.4 \pm 0.7^{\mathrm{a}}$ & $1.3 \pm 0.0$ & $3.1 \pm 0.1$ & $3.4 \pm 0.1^{\mathrm{a}}$ \\
\hline
\end{tabular}

Significant differences among species are indicated with different letters $(\mathrm{p}<0.05$ by One-Way ANOVA followed by Tukey's-test). Significant differences between gender were indicated by * $(\mathrm{p}<0.05)$ and ${ }^{* *}(\mathrm{p}<0.01)$ by Student's $t$ test. 
Table 3. Concentrations of chemicals in urine (means $\pm \mathrm{SE}$ ).

\begin{tabular}{|c|c|c|c|c|c|}
\hline & Order & & $\mathrm{Cl}^{-}$ & $\mathrm{Mg}^{2+}$ & $\mathrm{Ca}^{2+}$ \\
\hline Sex & Common name & $\mathrm{n}$ & $(\mathrm{mM})$ & $(\mathrm{mM})$ & $(\mathrm{mM})$ \\
\hline \multicolumn{6}{|c|}{ Males } \\
\hline & \multicolumn{5}{|l|}{ Cetacea } \\
\hline & Common minke whale & 10 & $290.8 \pm 22.6$ & $11.0 \pm 1.5^{\mathrm{a}}$ & $3.7 \pm 0.5^{\mathrm{b}}$ \\
\hline & Sei whale & 5 & $374.9 \pm 28.8$ & $21.2 \pm 4.5^{\mathrm{b}}$ & $2.6 \pm 0.8^{\mathrm{ab}}$ \\
\hline & Bryde's whale & 7 & $266.3 \pm 28.6$ & $11.2 \pm 2.0^{\mathrm{a}}$ & $1.4 \pm 0.4^{\mathrm{a}}$ \\
\hline & Sperm whale & 2 & $375.3 \pm 47.8$ & $19.5 \pm 0.5$ & $2.4 \pm 0.4$ \\
\hline & \multicolumn{5}{|l|}{ Artiodactyla } \\
\hline & Dromedary & 1 & 70.5 & 16.0 & 1.3 \\
\hline
\end{tabular}

Females

Cetacea

Common minke whale $\quad 3 \quad 267.2 \pm 53.6^{\text {bc }} \quad 20.7 \pm 3.9^{\mathrm{ab}} \quad 2.4 \pm 0.9$

Sei whale

$5 \quad 350.1 \pm 27.7^{\mathrm{c}} \quad 13.5 \pm 3.2^{\mathrm{ab}} \quad 1.3 \pm 0.5$

Bryde's whale

$5 \quad 224.9 \pm 31.8^{\mathrm{b}} \quad 10.0 \pm 2.5^{\mathrm{a}} \quad 1.4 \pm 0.4$

Sperm whale

$2 \quad 475.5 \pm 8.5 \quad 13.8 \pm 0.5 \quad 0.7 \pm 0.1$

Artiodactyla

$\begin{array}{lclll}\text { Bactrian camel } & 1 & 115.5 & 21.0 & 0.6 \\ \text { Cattle } & 10 & 111.4 \pm 6.3^{\mathrm{a}} & 23.8 \pm 2.6^{\mathrm{b}} & 6.1 \pm 1.5\end{array}$

Significant differences among species are indicated with different letters $(\mathrm{p}<0.05$ by One-Way ANOVA followed by Tukey's-test). 
Table 4. Plasma levels of testosterone, estradiol, and progesterone (means \pm SE) and reproductive status of experimental animals.

\begin{tabular}{clllll}
\hline sex & $\begin{array}{c}\text { Order } \\
\text { Common name }\end{array}$ & $\begin{array}{l}\text { Reproductive } \\
\text { status }\end{array}$ & $\begin{array}{l}\text { Testosterone } \\
(\mathrm{ng} / \mathrm{ml})\end{array}$ & $\begin{array}{l}\text { Estradiol } \\
(\mathrm{ng} / \mathrm{ml})\end{array}$ & $\begin{array}{l}\text { Progesterone } \\
(\mathrm{ng} / \mathrm{ml})\end{array}$ \\
\hline Male & Cetacea & & & \\
& Common minke & Immature & 2 & $0.21 \pm 0.03$ & \\
whale & Mature & 12 & $0.28 \pm 0.05$ & \\
& Immature & 1 & 2.62 & \\
Sei whale & Mature & 5 & $1.68 \pm 0.23$ & \\
& Immature & 4 & $0.17 \pm 0.04$ & \\
Bryde's whale & Mature & 3 & $2.15 \pm 1.23$ & \\
& ND & 2 & $1.62 \pm 0.03$ & \\
Sperm whale & & & & \\
Artiodactyla & Mature & 1 & 0.68 & \\
Dromedary & & & & \\
\hline
\end{tabular}

\section{Femal Cetacea}

e

\begin{tabular}{lllll} 
Common minke & Immature & 6 & $0.57 \pm 0.26$ & $1.50 \pm 0.45$ \\
whale & & & & \\
& Pregnant & 2 & $0.13 \pm 0.03$ & $12.1 \pm 0.26$ \\
& Resting & 1 & 0.02 & $\mathrm{ND}^{2}$ \\
Sei whale & Pregnant & 6 & $0.14 \pm 0.07$ & $6.60 \pm 0.86$ \\
Bryde's whale & Immature & 1 & 0.03 & $\mathrm{ND}^{2}$ \\
& Pregnant & 3 & $0.20 \pm 0.09$ & $4.11 \pm 1.88$ \\
& Lactating/Rest & 2 & $0.03 \pm 0.00$ & $0.11 \pm 0.00$ \\
& ing & & & \\
Sperm whale & Immature & 1 & 0.03 & 0.18 \\
& Ovulating/Res & 2 & $0.02 \pm 0.01$ & 0.35 \\
& ting & & & \\
rtiodactyla & & & & \\
Cattle & Immature & 5 & $0.04 \pm 0.01$ & $5.38 \pm 1.27$ \\
& Lactating & 5 & $0.03 \pm 0.01$ & $2.83 \pm 0.75$ \\
Bactrian camel & Mature & 1 & 0.25 & 3.26 \\
\hline
\end{tabular}

$\mathrm{ND}^{1}$ : not determined; $\mathrm{ND}^{2}$ : not detected. 
Table 5. Some positive and negative correlation coefficients $(r)$ of variables.

\begin{tabular}{|c|c|c|c|c|c|c|c|c|}
\hline \multirow[b]{2}{*}{ Variables } & & \multicolumn{3}{|l|}{ Male } & \multicolumn{4}{|l|}{ Female } \\
\hline & & Minke & Sei & Bryde's & Minke & Sei & Bryde's & Cattle \\
\hline Body length & Body weight & $0.959^{* *}$ & $0.902^{*}$ & $0.909^{* *}$ & $0.985^{* * *}$ & & $0.952^{* *}$ & \\
\hline Lag time & Plasma K ${ }^{+}$ & $0.535^{*}$ & & $0.933^{* *}$ & & & & \\
\hline \multicolumn{9}{|l|}{ Plasma } \\
\hline \multirow[t]{7}{*}{ osmolality } & Plasma $\mathrm{Na}^{+}$ & $0.968^{* *}$ & & $0.973^{* *}$ & $0.942^{* *}$ & $0.814^{*}$ & $0.840^{*}$ & \\
\hline & Plasma $\mathrm{Cl}^{-}$ & $0.932^{* *}$ & & $0.921^{* * *}$ & $0.832^{* *}$ & & $0.838^{*}$ & \\
\hline & Plasma $\mathrm{K}^{+}$ & $0.764^{* *}$ & & & & $0.872^{*}$ & & \\
\hline & Plasma $\mathrm{Mg}^{2+}$ & $0.637^{*}$ & & $0.838^{*}$ & & & & \\
\hline & Plasma $\mathrm{Ca}^{2+}$ & $0.919^{* *}$ & & $0.980^{* *}$ & & $0.960^{* *}$ & & \\
\hline & Plasma urea & $0.612^{*}$ & & & & & & \\
\hline & Cortisol & $0.741^{* *}$ & & & & & & \\
\hline Plasma $\mathrm{Na}^{+}$ & Aldosterone & & $-0.848^{*}$ & & & & & \\
\hline \multirow[t]{3}{*}{ Plasma glucose } & Corticosterone & & & & & & $0.820^{*}$ & \\
\hline & Testosterone & & & & & & $0.935^{* *}$ & \\
\hline & Progesterone & & & & & & & $0.651^{*}$ \\
\hline \multicolumn{9}{|l|}{ Urinary } \\
\hline \multirow[t]{4}{*}{ osmolality } & Urinary $\mathrm{Na}^{+}$ & & & & & & $0.949^{*}$ & \\
\hline & Urinary $\mathrm{Cl}^{-}$ & & $0.893^{*}$ & & & & $0.954^{*}$ & \\
\hline & Urinary $\mathrm{K}^{+}$ & $0.769^{* *}$ & & & & $0.961^{* *}$ & & \\
\hline & Urinary urea & & & $0.846^{*}$ & & $0.981^{* *}$ & $0.978^{* * *}$ & $0.840^{* *}$ \\
\hline Urinary $\mathrm{Na}^{+}$ & Aldosterone & & & & & $-0.971^{*}$ & & \\
\hline \multirow[t]{4}{*}{ Aldosterone } & Cortisol & $0.817^{* *}$ & & & & & & \\
\hline & Corticosterone & $0.647^{*}$ & $0.873^{*}$ & & $0.758^{*}$ & & $0.983^{*}$ & \\
\hline & Testosterone & $0.868^{* *}$ & $0.909^{*}$ & & & & & \\
\hline & Estradiol & $0.792^{* * *}$ & $0.989^{* *}$ & & $0.960^{* *}$ & $0.901^{*}$ & $0.992^{* * *}$ & \\
\hline \multirow[t]{4}{*}{ Cortisol } & Corticosterone & $0.769^{* *}$ & $0.986^{* *}$ & & & & & \\
\hline & Testosterone & $0.537^{*}$ & & & & & & \\
\hline & Progesterone & & $0.990^{* *}$ & & & & & \\
\hline & Estradiol & & & $0.983^{* *}$ & & & & \\
\hline
\end{tabular}

Significant correlations are indicated with ${ }^{*}(\mathrm{p}<0.05)$ and ${ }^{* *}(\mathrm{p}<0.01)$ determined by Pearson's correlation coefficient. 


\section{Figure Legends}

Fig. 1. Plasma and urine osmolality (means $\pm \mathrm{SE}, \mathrm{mOsm} / \mathrm{kg}$ ) in the common minke, sei, Bryde's and sperm whales, and dromedary, Bactrian camel and cattle. Significant differences among species are indicated with different letters $(\mathrm{p}<0.05$ by One-Way ANOVA followed by Tukey's-test).

Fig. 2. Concentrations of $\mathrm{Na}^{+}(\mathrm{mM}$, means $\pm \mathrm{SE})$ in plasma (A) and urine (B) of common minke, sei, Bryde's and sperm whales, and dromedary, Bactrian camel and cattle. Significant differences among species are indicated with different letters ( $\mathrm{p}<0.05$ by One-Way ANOVA followed by Tukey's-test).

Fig. 3. Concentrations of $\mathrm{K}^{+}(\mathrm{mM}$, means $\pm \mathrm{SE})$ in plasma (A) and urine (B) of common minke, sei, Bryde's, and sperm whales and dromedary, Bactrian camel and cattle. Significant differences among species are indicated with different letters ( $\mathrm{p}<0.05$ by One-Way ANOVA followed by Tukey's-test). ND: not determined.

Fig. 4. Concentrations of urea $(\mathrm{mM}$, means $\pm \mathrm{SE})$ in the plasma (A) and urine (B) of common minke, sei, Bryde's and sperm whales, and dromedary, Bactrian camel and cattle. Significant differences among species are indicated with different letters ( $p<0.05$ by One-Way ANOVA followed by Tukey's-test).

Fig. 5. Plasma concentrations (means $\pm \mathrm{SE}$ ) of aldosterone in the common minke, sei, Bryde's and sperm whales and dromedary, Bactrian camel and cattle. Significant differences among species are indicated with different letters $(p<0.05$ by One-Way ANOVA followed by Tukey's-test). Significant differences between gender were indicated by * $(\mathrm{p}<0.05)$ by Student's $t$ test.

Fig. 6. Plasma concentrations (means $\pm \mathrm{SE}$ ) of cortisol (A) and corticosterone (B) in the common minke, sei, Bryde's and sperm whales and dromedary, Bactrian camel and cattle. Significant differences among species are indicated with different letters $(\mathrm{p}<0.05$ by One-Way ANOVA followed by Tukey's-test). Significant differences between gender were indicated by ** $(\mathrm{p}<0.01)$ by Student's $t$ test. 
Fig. 1 Birukawa et al.

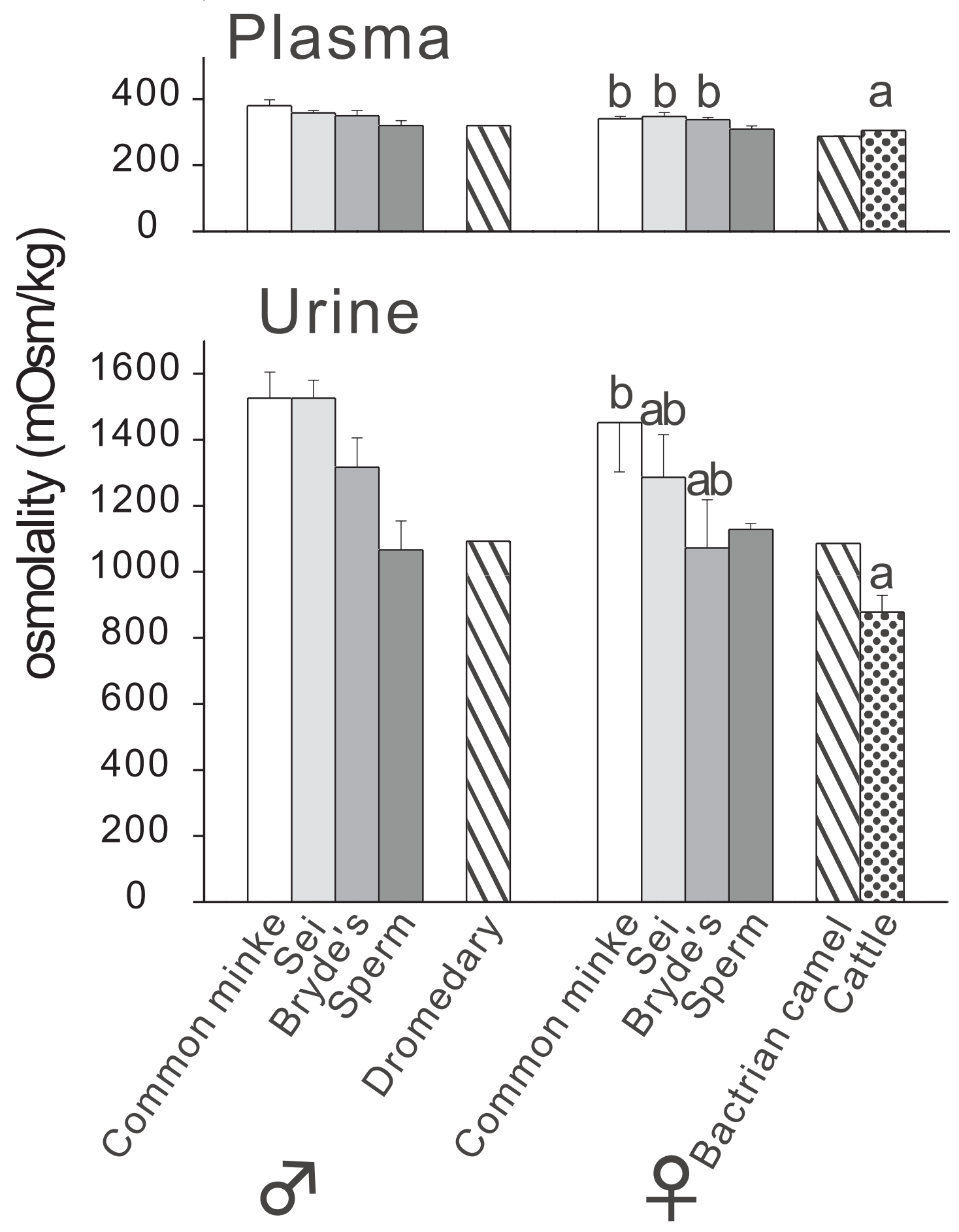


Fig. 2 Birukawa et al.

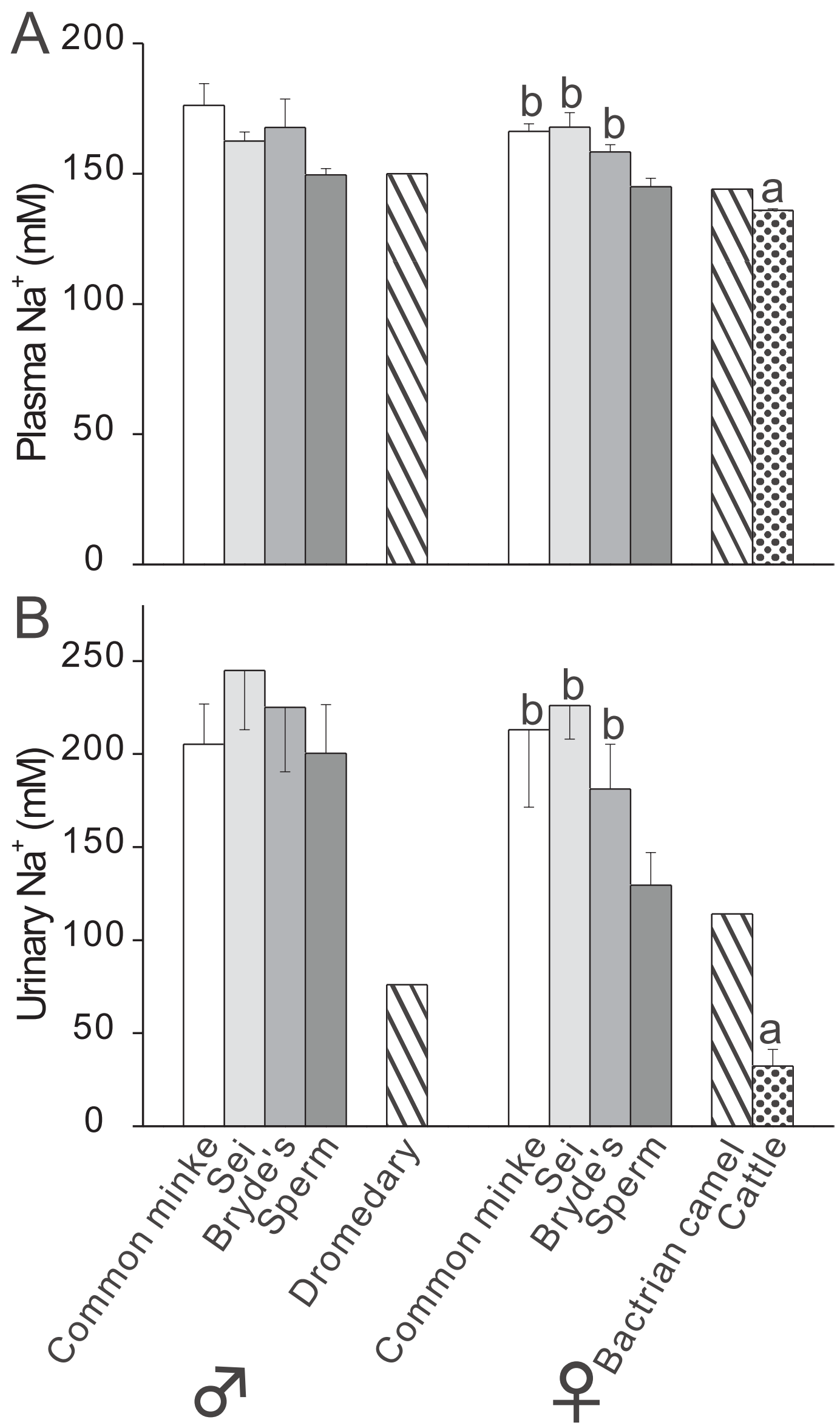


Fig. 3 Birukawa et al.
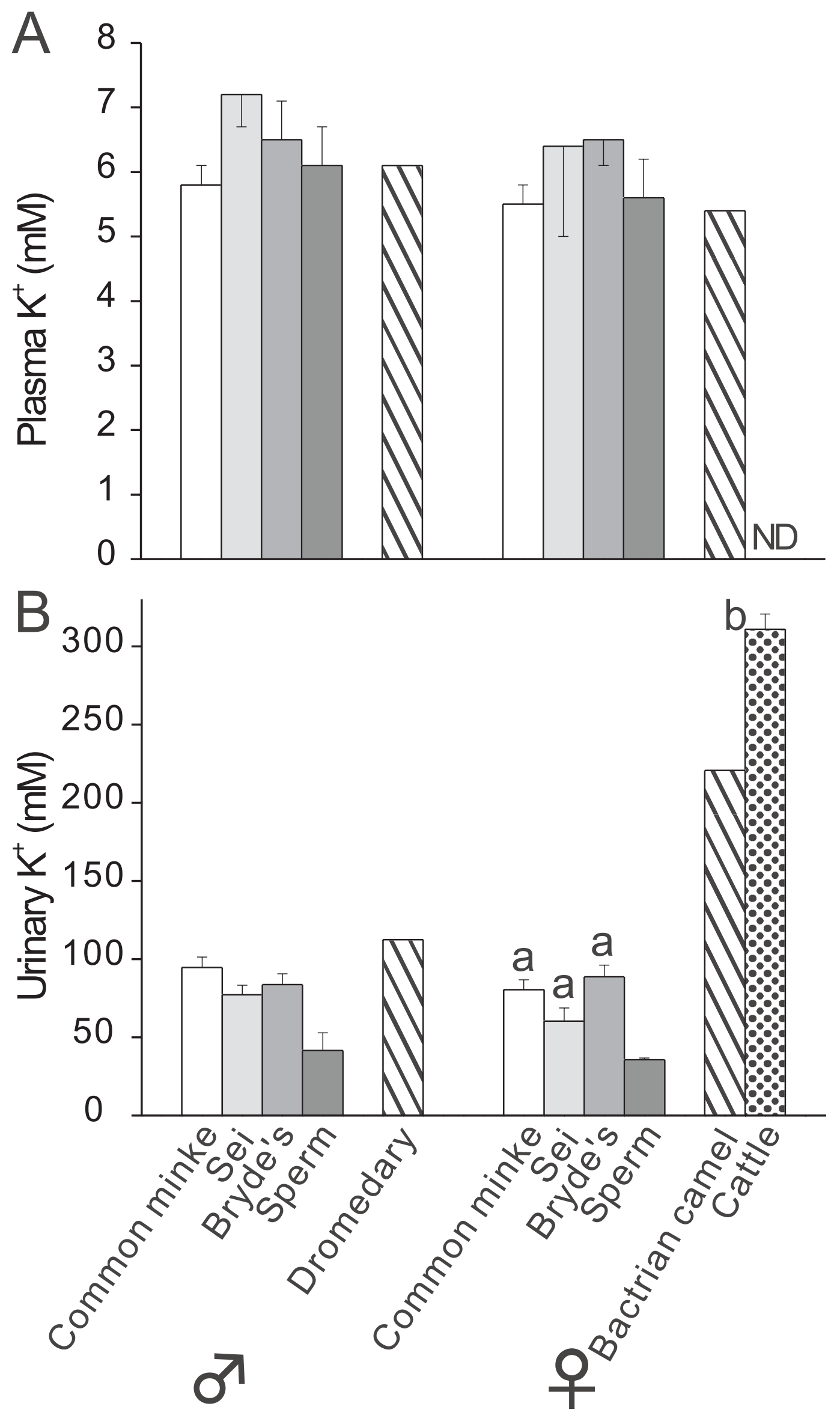
Fig. 4 Birukawa et al.

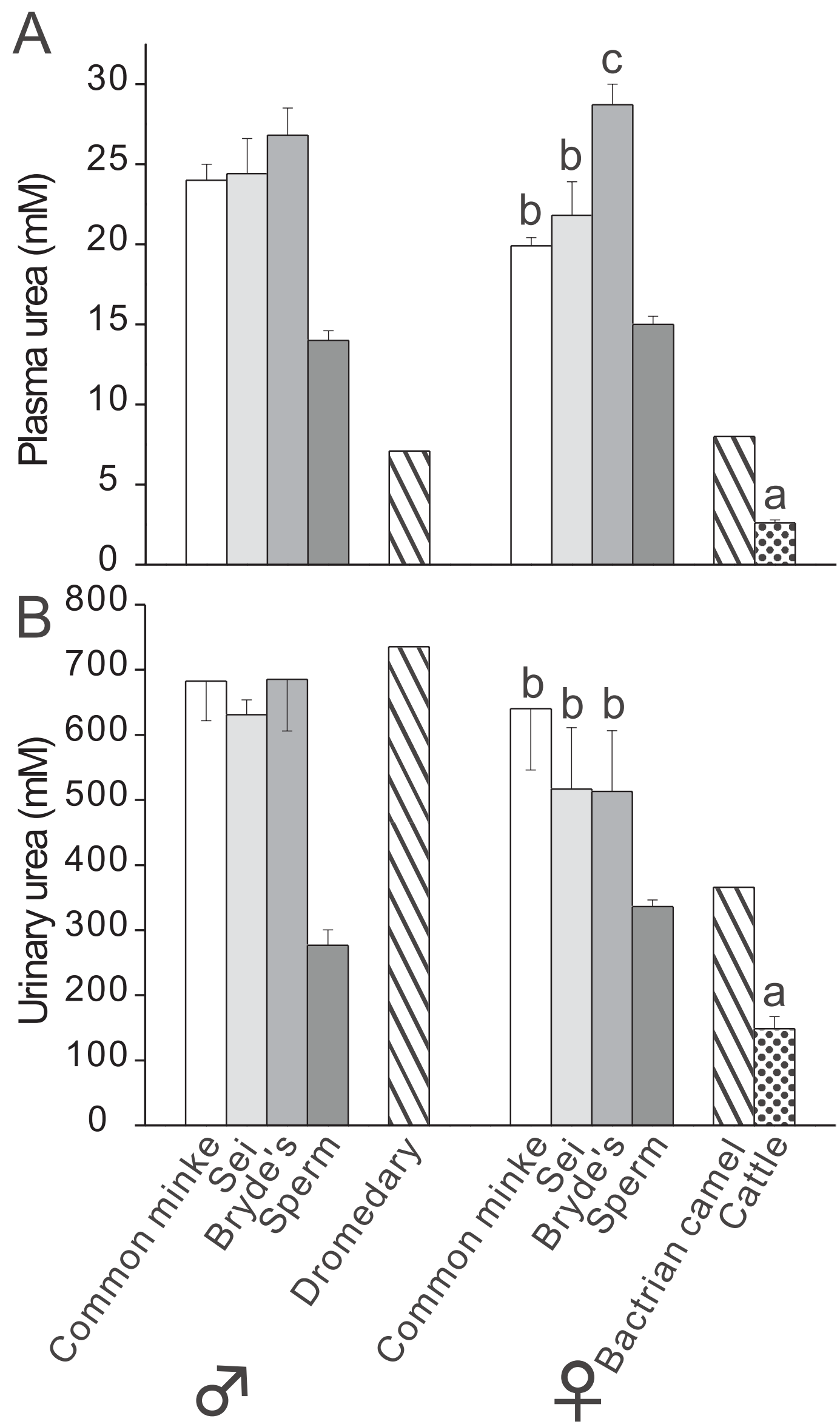


Fig. 5 Birukawa et al.

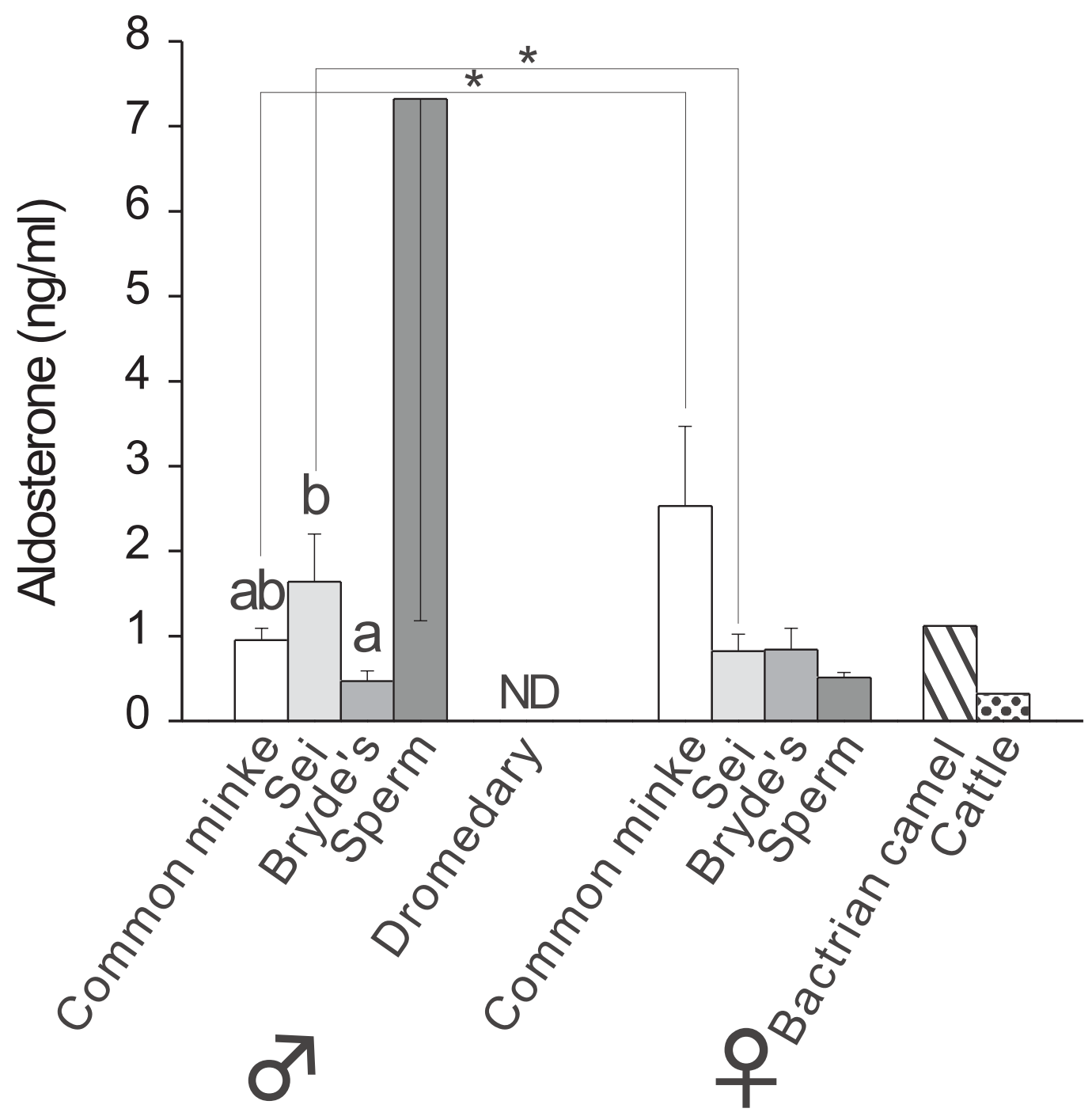


Fig. 6 Birukawa et al.
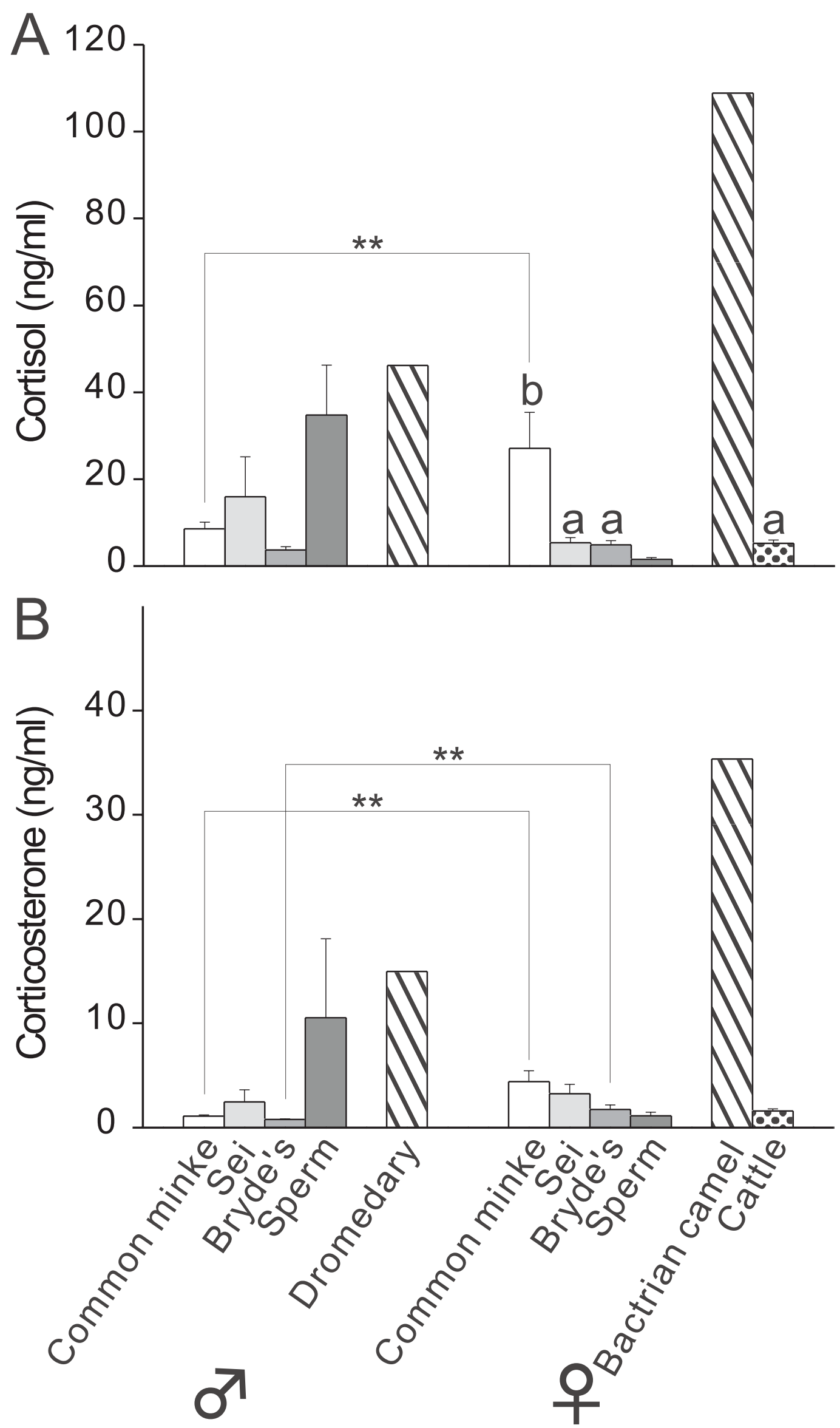